\title{
Alaa H. J. Al-Rkaby* \\ Strength and Deformation of Sand-Tire Rubber Mixtures (STRM): An Experimental Study
}

https://doi.org/10.2478/sgem-2019-0007

received December 2, 2018; accepted February 14, 2019.

Abstract: Waste material such as used tires is increasing every year, which poses environmental problems. However, such material has been used in several geotechnical applications as alternative lightweight backfill in highway embankments and/or behind retaining walls, providing environmental, economic and technical benefits. These applications require knowledge of engineering properties of soil-tire rubber mixtures. The present study aims to show the possibility of tire rubber usage in sand by evaluating the shear strength and deformability of sand mixed with granulated rubber, in weight percentages between 0 and 50\%. The tire rubber content was found to influence the stress-strain and deformation behavior of the mixtures. The shear strength of sand mixed with $10 \%$ or 20\% tire rubber was higher than that measured for sand only. However, the trend for TRC $=30-50 \%$ was different. Samples with a rubber content of $30-50 \%$ exhibited a rapid decrease in the stress ratio compared with that of sand. The major principal strain at maximum stress ratio was found to increase with increasing tire rubber content. However, it was observed that the lateral strains (minor and intermediate principal strains) of samples reduced significantly with the addition of tire rubber to the sand.

Keywords: Tire rubber; shear strength; deformation; major; minor and intermediate principal strains.

\section{Introduction}

Management of solid waste is a major environmental concern worldwide. Annually, 1.5 billion of tires around the world get out of utilizing cycle. For example, 46 million tires are disposed of in the U.K. These wastes cause a major health hazards for both human beings and

\footnotetext{
*Corresponding author: Alaa H. J. Al-Rkaby, Civil Engineering Department, Thi Qar University, Iraq; Curtin University, Australia, E-mail:a.al-rkaby@postgrad.curtin.edu.au
}

animals. ${ }^{[1]}$ Therefore, disposal of the used tires in landfills has been banned. Thus, recycling of these waste tires needs to be considered. There is a potential of using scrap tires in many geotechnical applications such as building foundations, light-rail construction, road construction, slope stabilization, backfill for bridge abutment and retaining walls. ${ }^{[2-7]}$ Such admixing of scrap tire rubber (STR) has received great acceptance and application in the last two decades in several geostructures, as this approach offers economic benefits compared with traditional techniques. Some properties of such scrap tire rubber are high compressibility, lightweight, high thermal insulation, good long-term durability compared to other

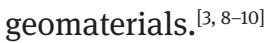

Some studies found that adding rubber materials resulted in improving the shear strength of soil. ${ }^{[1-13]}$ However, many other studies such as Kawata et al., ${ }^{[14]}$ Neaz Sheikh et al. ${ }^{[15]}$ and Youwai and Bergado ${ }^{[16]}$ have reported significant reduction in the strength of soil due to added rubber materials. Tafreshi et al. ${ }^{[8]}$ found that by using tire shreds-sand mixtures over the pipe resulted in significant decrease in the pressure distributed over the pipe, pipe deflection and the soil surface settlement. Furthermore, it was found that shredded rubber mixed with well graded sand has a better performance on the pipe responses compared with chipped rubber. Mohamad et al. ${ }^{[3]}$ investigated the shear strength parameters of sand mixed with different contents of tire chips (10-50\% by weight). They found that $10 \%$ of the used tire chips can improve the internal friction angle and the shear strength of sand. Similar trend was observed by Saberian et al. ${ }^{[9]}$ who found that by adding $20 \%$ shredded tire chips to sandy peat resulted in increasing the angle of internal friction and cohesion to $39.8^{\circ}$ and $94.8 \mathrm{kPa}$ respectively compared with $17.8^{\circ}$ and $11.2 \mathrm{kPa}$ for the untreated samples. Moreover, specimen with $10 \%$ tire chips provided the maximum unconfined compression strength. This trend is agreed with the findings of Cetin et al., ${ }^{[17]}$ Akbulut et al. ${ }^{[18]}$ and Gotteland et al. $^{[18]}$ Moreover, most of the geo-material exhibited directional dependence of the mechanical properties. ${ }^{[20-22]}$ Behavior of the mixture is significantly affected by rubber content and rubber-sand particle size 


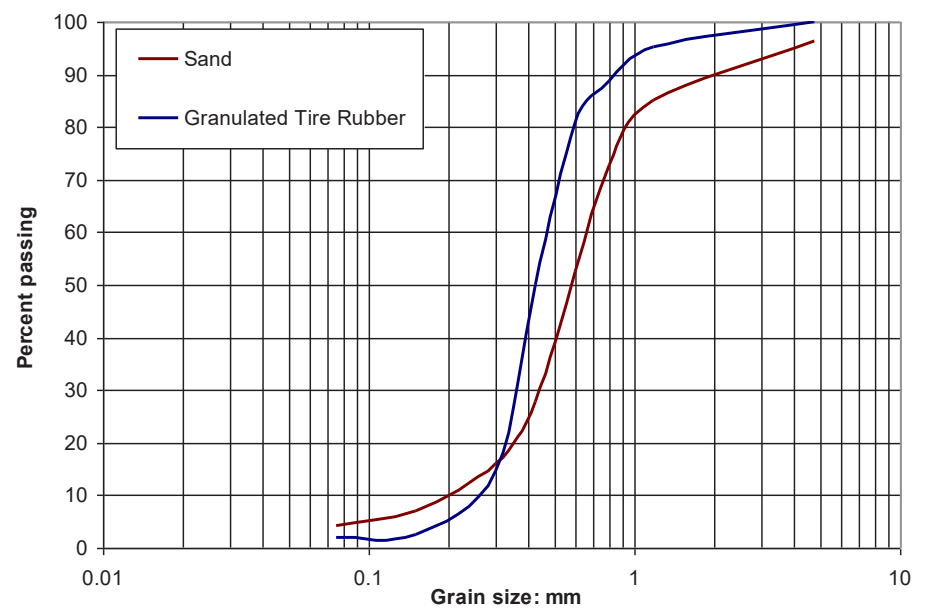

(a)

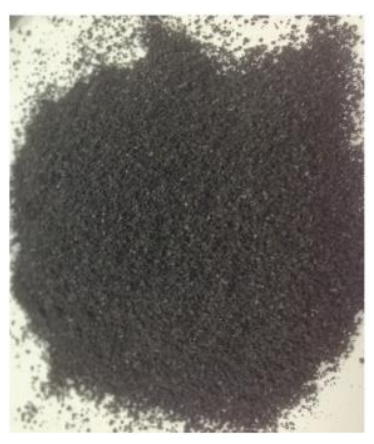

(b)

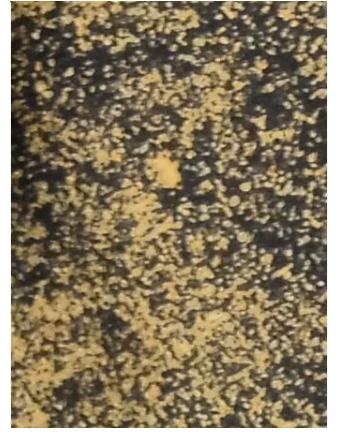

(c)

Figure 1: (a) Grain size distribution curves of the used sand and granulated tire rubber, (b) Scrap tire rubber and (c) Sand-tire rubber mixture.

ratio in a manner that increase in the former and decrease in the later, resulting in softer behavior, lowers stiffness and lower strength. ${ }^{[6]}$

Damping ratio of the sand-rubber mixtures increases and the shear modulus systematically decreases with an increase in the granulated rubber content. ${ }^{[10]}$ The large strain stiffness of the sand-rubber mixtures decreases as the rubber content increases. ${ }^{[4]}$ Conversely, the criticalstate friction angles increases from $28.9^{\circ}$ for untreated sand to $32.0^{\circ}$ for sand that contained $20 \%$ of rubber and tested at similar states. ${ }^{[4]}$

It is apparent that soil-scrap tire can be used in many geostructures as alternative backfill material. Such soft rubber particles significantly change the mechanical properties of soil. However, very little attention was given to its effect on the deformation of sand. Therefore, the present study was conducted with the aim of investigating the deformation of rubber sand mixtures, and how long the granulated tire rubber could reduce the lateral strain.

\section{Laboratory and Field Testing Program Materials}

\subsection{Used Sand}

The soil samples used in the present study is classified as poorly graded sand according to the Unified Soil Classification System. The specific gravity of solids is 2.61 Gs value, which is low here due to the presence of gypsum $\mathrm{CaSO}_{4} \cdot 2 \mathrm{H}_{2} \mathrm{O}$ in the composition of the used sand.

\subsection{Granulated Tire Rubber (GTR)}

The granulated rubber used in this study is the by-product of the shredding process of used tires. Rubber particles were sieved to obtain a uniform size. The rubber material was angular and irregularly shaped, and has specific gravity (determined in accordance with ASTM D 854), 


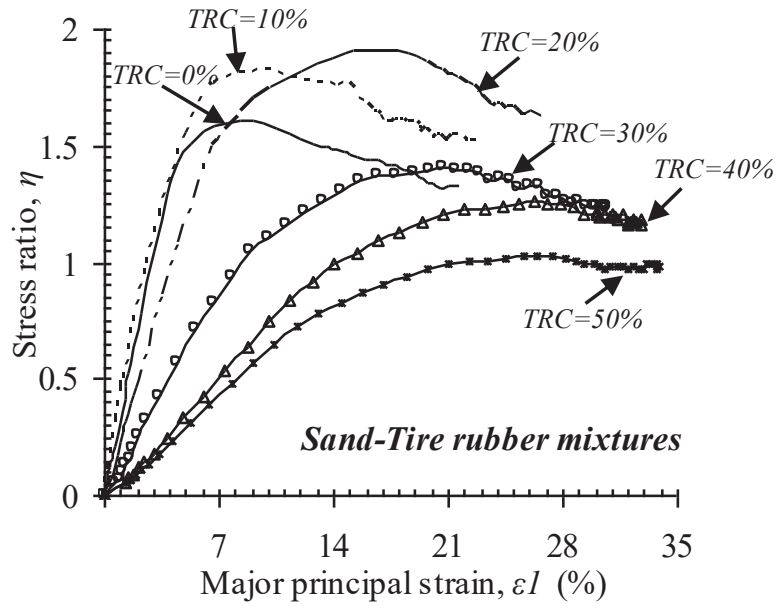

(a)

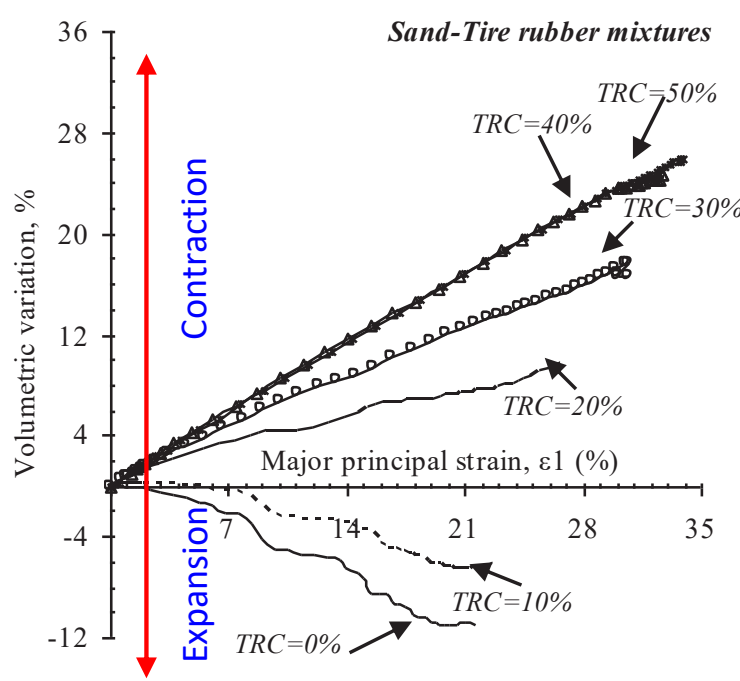

(b)

Figure 2: Relationship between (a) stress ratio and major principal strain and (b) volumetric variation and major principal strain of specimens based on different contents of tire rubber.

maximum and mean particle sizes of such rubber of 1.1, $4.75 \mathrm{~mm}$ and $0.43 \mathrm{~mm}$ respectively.

\section{Methodology}

Tire rubber contents by mass, $T R C \%$, were selected as 0, 10, 20, 30, 40 and 50\%. Its corresponding contents by volume were $0,19.9,35.9,48.9,59.9$ and 69.1\%, respectively. It was important to avoid any segregation during the specimens' preparation that could influence the results of the experiments. Therefore, special care was taken to thoroughly mix the sand and tire rubber from the beginning till pouring them into the mold to produce a reasonably uniform, non-segregated mixture. After mixing the appropriate amount of dry sand and tire rubber, specimens were constructed carefully using the dry deposition method in six layers. Every layer was tamped using a metal rod tamper providing almost relative density of $80 \%$. Tests have been performed based on ASTM D7181-11. After the sample had been set up in the cell with vacuum pressure $(25 \mathrm{kPa})$, the inner and outer chambers were filled with de-aired water and the saturation process was carried out by applying different values of back pressure, while keeping a constant initial effective stress of $30 \mathrm{kPa}$ until obtaining a Skempton's B-value greater than 0.95 . Then, the specimen was consolidated isotropically by ramping the effective confining pressure (outer and inner) up to $200 \mathrm{kPa}$.

\section{Results}

The stress-strain characteristics of sand-tire rubber mixtures are illustrated in Figure 2. The stress ratio can be defined as the ratio of the major principal stress to the minor one. The highest level of stress ratio obtained from stress ratio-major principal strain curve is defined as the maximum stress ratio. Radial displacements were obtained by using radial chain device that was supplemented by a number of sensors and mounted around the sample.

Figure 3 shows the variation of the maximum stress ratio $\eta$ max along the tire rubber content TRC of 10, 20, 30, 40 and $50 \%$. It is clear that maximum stress ratio $\eta \max$ of sand increased from 1.61 to 1.83 and 1.90 as the tire rubber content TRC increased to 10 and $20 \%$. After that, the maximum stress ratio decreased dramatically to 1.41 , 1.26 and 1.03 for $T R C=30,40$ and $50 \%$ respectively. This means that stress ratio increased by 13.6 and $18.0 \%$ as TRC increased to 10 and $20 \%$ respectively, followed by decreasing by $12.4,21.7$ and $36.0 \%$ when TRC increased to 30,40 and $50 \%$ respectively. This trend is similar to the results presented in Mashiri et al. ${ }^{[2]}$

It is well known that the shear strength of clean sand depends totally on the friction between particles and, thus, the presence of tire rubber material as inter-particle layers affects friction and thereby stability. The increase in stress ratio associated with $T R C=10$ and $20 \%$ is related to the fact that such a percentage likely fills the voids between sand particles, which prevents particles from moving and sliding easily under shearing; and consequently, exhibit higher values of strength. This means that $T R C=10-20 \%$ 


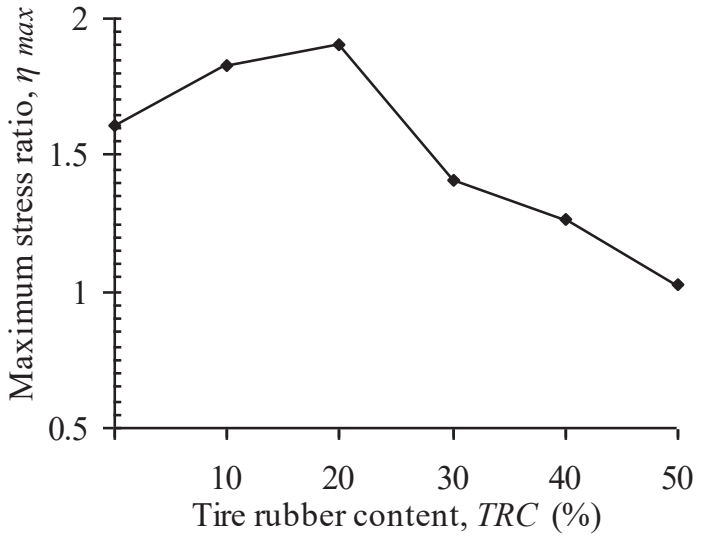

Figure 3: Effect of rubber content on maximum stress ratio of mixtures.

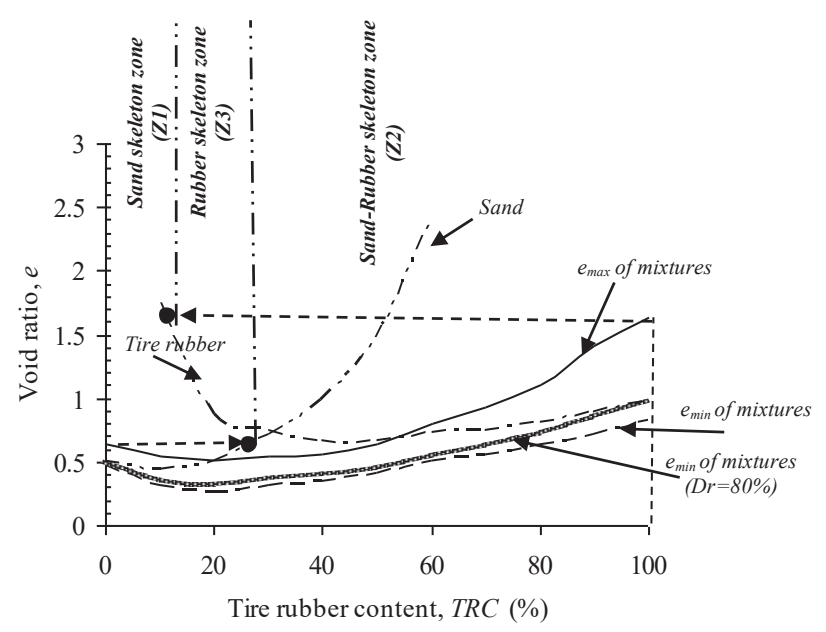

Figure 4: The variation in the maximum and minimum void ratio of sand-rubber mixtures, void ratio of mixtures $(D r=80 \%)$, void ratio of the sand and the rubber in the mixtures $(\mathrm{Dr}=80 \%)$

is likely to be the optimum tire rubber content. However, the decrease in the stress ratio that occurred in sand when $T R C \geq 30 \%$ is attributed to the fact that rubber material can be deformed vertically significantly under the applied load. Moreover, the particles in mixtures with high rubber content can move and slide easily under shearing; and consequently, exhibit lower values of stress ratio. This is consistent with the results of several researchers [such 2, 3 and 9]. However, Ehsani et al. ${ }^{[6]}$ reported a different trend.

This variation in the maximum stress ratio $\eta$ max with the tire rubber content TRC can be explained based on the variation of the void ratio of the sand-tire rubber mixtures STRM with the tire rubber content. ${ }^{[2]}$ Figure 4 illustrates that the lowest value of the maximum emax and minimum emin void ratio occurred at $T R C=20.0 \%$. Moreover, the maximum void ratio of rubber intersected the void ratio curve of rubber at $\mathrm{TRC}=11.6 \%$, while the maximum void ratio of sand intersected the void ratio curve of sand at TRC $=26.7 \%$. The shearing behavior of the sand-tire rubber mixtures STRM can be divided into three distinct zones, Z1, Z2 and Z3. First zone is the sand matrix zone for mixtures that have less than $11.6 \%$ of rubber. In this zone, sand forms the main skeleton. However, rubber can occupy inter-particular voids to provide a cushioning effect and improve interlocking between sand particles. For rubber content between 11.6 and $26.7 \%$, both rubber and sand form the skeleton of mixtures and share the applied load. Increasing the rubber content beyond 26.7\% causes the behavior of the mixture to be controlled by the rubber. This agrees with Mashiri et al. ${ }^{[2]}$ who have presented similar explanation. This means that the improvement in the mixture is related to improving bonding and cushioning effect provided by the tire rubber occupying the inter-granular voids, which improves resistance to induced lateral forces by decreasing the amount of sliding and rotation of particles along the bedding plane.

Figures 5(a-f) show the accumulated principal strains with the stress ratio. It was found that maximum stress ratio $\eta$ max of sand-tire rubber mixtures STRM occurred at major principal strain $\varepsilon_{1}$ larger than that of clean sand. Moreover, as the rubber content increased such major principal strain increased. For example, the maximum stress ratio of sand (1.61) occurred at major principal strain $\varepsilon_{1}$ of $9.1 \%$, while the maximum stress ratio of the sand-tire rubber mixtures occurred at 9.8, 17.2, 20.7, 26.2 and 26.4\% for rubber content of 10, 20, 30, 40 and 50\% respectively. This means that increasing rubber content from $0 \%$ to $50 \%$ resulted in increasing $\varepsilon_{1}$ by $169 \%$, indicating that the behavior becomes softer. Moreover, sand containing 40 and $50 \%$ of rubber failed when $\varepsilon_{1}$ reached $33.6 \%$ compared with $21.3 \%$ for clean sand. It is evident that tire rubber material TRM contributes significantly to the sustaining of applied loads even under large strains due to its elastic nature.

Regarding the effect of tire rubber on the induced lateral deformation, it was found that tire rubber material TRM has significant effects on such lateral strains, $\varepsilon_{283^{\circ}}$ For clean sand, the minor strain $\varepsilon_{3}$ increased steadily with increasing the applied load and reached $5.2 \%$ at the maximum stress ratio $\eta_{\max }$ and $14.5 \%$ at failure. Minor principal strain $\varepsilon_{3}$, however, decreased clearly when tire rubber material TRM was added to sand. For example, at the maximum stress ratio $\eta_{\max }=1.61, \varepsilon_{3}$ decreased to 5.0, 4.8, 3.6, 2.2 and $2.1 \%$ as the rubber content increased to 10 , 20, 30, 40 and 50\% respectively, compared with $5.2 \%$ for clean sand. When the specimen failed, the accumulated $\varepsilon_{3}$ 


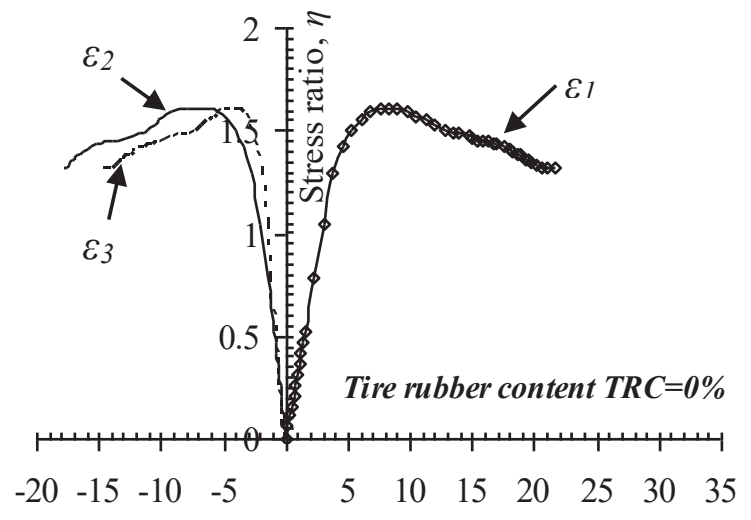

Principal strain, $\varepsilon 1,2,3(\%)$

(a) $T R C=0 \%$

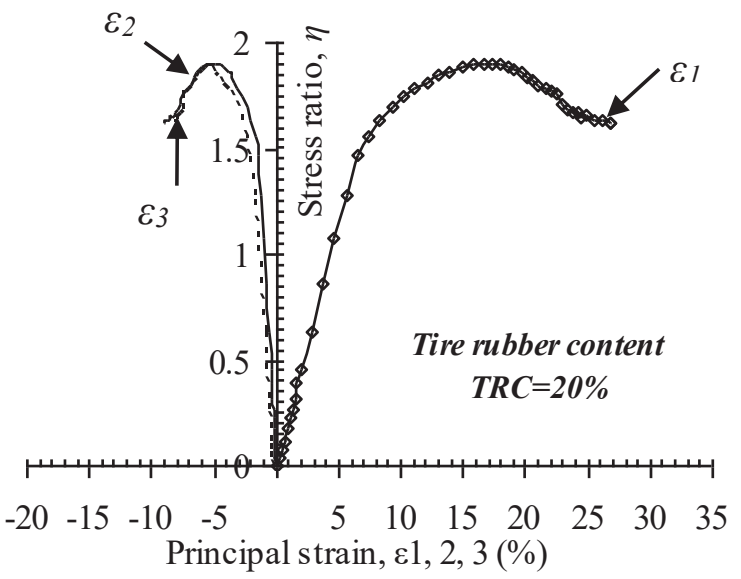

(c) $T R C=20 \%$

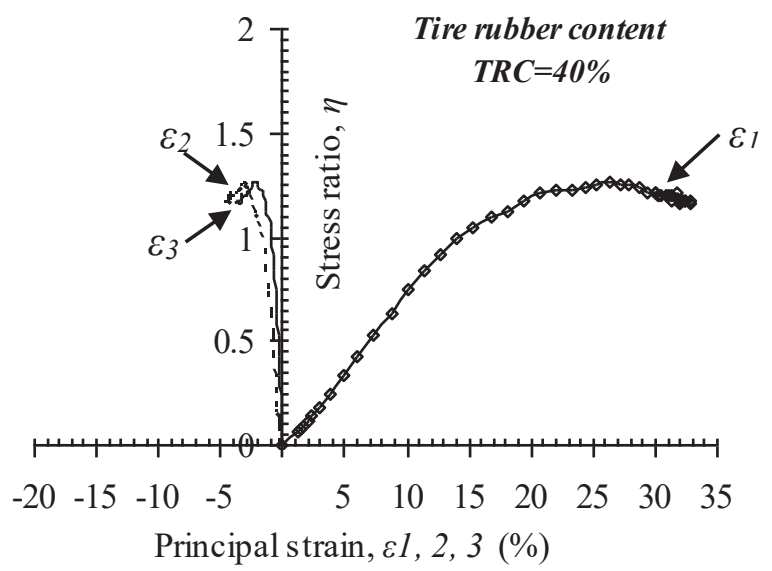

(e) $T R C=40 \%$

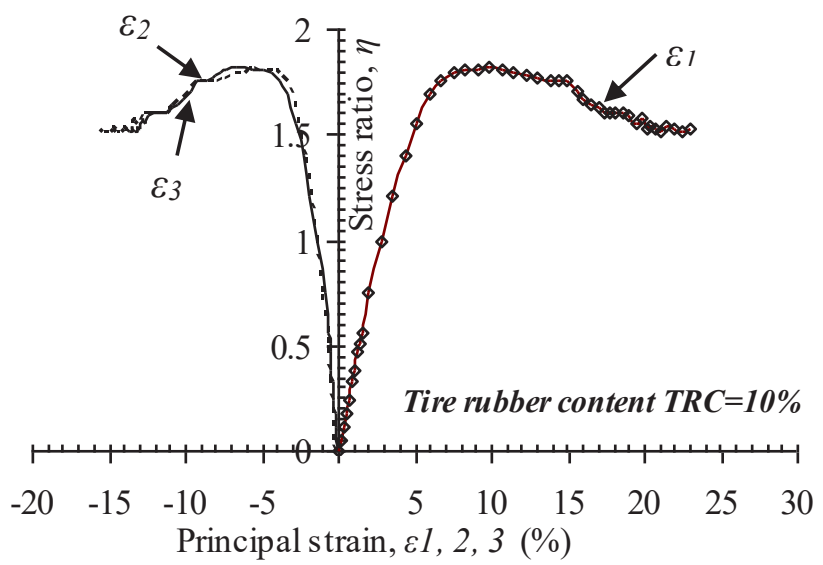

(b) $T R C=10 \%$

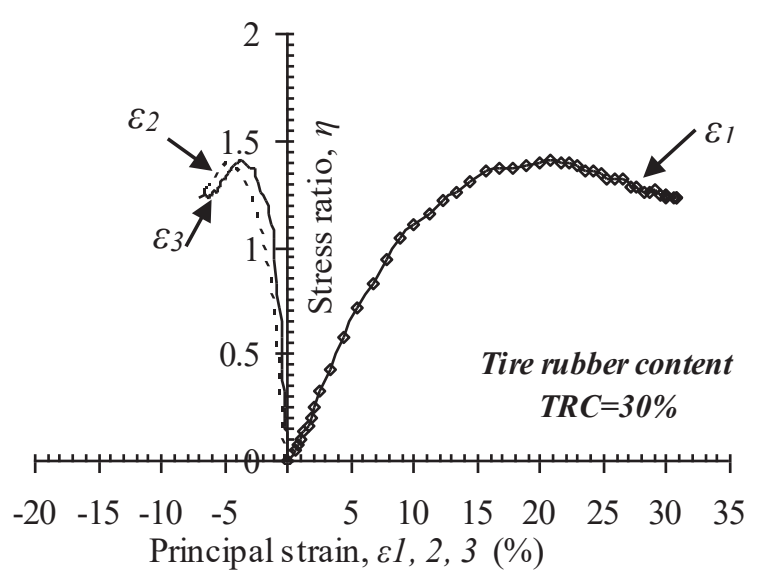

(d) $T R C=30 \%$

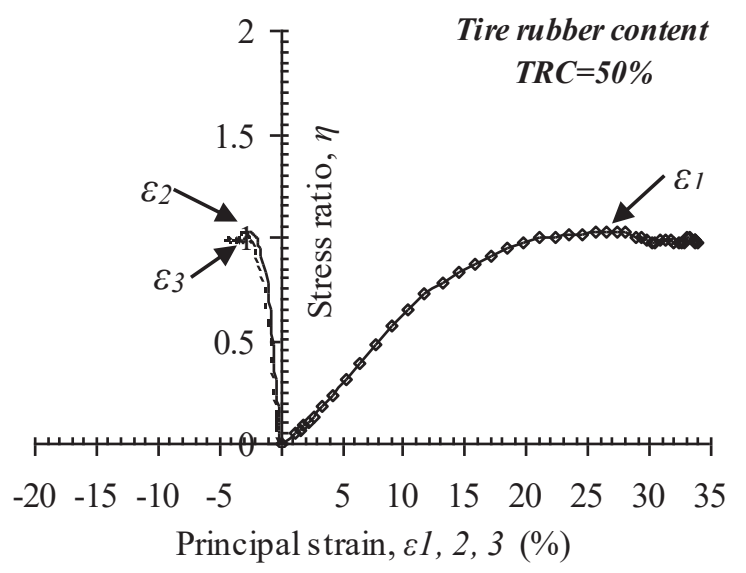

(f) $T R C=50 \%$

Figure 7: Relationships between principal strains and stress ratio for sand mixed with different contents of tire rubber 
was only 3.7\% for sand containing 50\% rubber compared with $14.5 \%$ for clean sand. Adding tire rubber material showed similar effect on the intermediate principal strain $\varepsilon_{2}$. For example, sand with $10,20,30,40$ and $50 \%$ rubber exhibited $\varepsilon_{2}$ of only $6.6,5.1,4.5,2.9$ and $2.3 \%$ respectively compared with $8.0 \%$ for clean sand. Results of both intermediate and minor principal strains indicated that TRM effectively restrained lateral deformation. Therefore, such mixtures can be used effectively as backfill behind retaining walls to decrease the induced lateral pressure.

\section{Conclusions}

The main objective of this study was to evaluate the effects of scrap tire rubber on the geomechanical characteristics of sand. In order to achieve such an object, a series of drained triaxial tests were conducted on sand mixed with $0,10,20,30,40$ and $50 \%$ tire rubber. The results obtained in this study can be summarized as follows:

1. Minimum emin and maximum emax void ratio of sand-tire rubber mixtures decreased as the tire rubber content $T R C$ increased to $20 \%$, then increased dramatically with $30-50 \%$ tire rubber.

2. The behavior of mixtures can be divided into three zones based on the content of the tire rubber: i. Sand skeleton zone (for $T R C \leq 11.6 \%$ ), ii. Sand-rubber skeleton zone (for TRC between $11.6 \%$ and $28.7 \%$ ), and iii. Rubber skeleton zone (for TRC > 28.7\%).

3. Results showed that maximum stress ratio increased by 13.6 and $18.0 \%$ when 10 and $20 \%$ of tire rubber was added to sand respectively. However, stress ratio then decreased by $12.4,21.7$ and $36.0 \%$ for $T R C=30$, 40 and 50\% respectively compared with sand. This trend agrees generally with the aforementioned three behavioral zones.

4. Adding tire rubber to sand resulted in an increase in the major principal strain, indicating that the behavior changed to being more ductile. However, minor and intermediate principal strains of sand-tire rubber mixtures decreased significantly compared with sand. This indicates that sand-rubber mixtures can be used effectively behind the retaining wall to eliminate the lateral earth pressure.

\section{References}

[1] M. F. Attom, "The use of shredded waste tires to improve the geotechnical engineering properties of sands," Environ. Geol., 49(4), 497-503 (2006).

[2] M. S. Mashiri, J. S. Vinod, M. N. Sheikh, and H. H. Tsang, "Shear strength and dilatancy behaviour of sand-tyre chip mixtures," Soils Found., 55(3), 517-528 (2015).

[3] E. T. Mohamad, N. Latifi, A. Marto, R. Moradi, and S. V. A. N. K. Abad, "Effects of relative density on shear strength characteristics of sand-tire chips mixture," EJGE, 18, 623-632 (2013).

[4] J. Dunham-Friel, and J. A. H. Carraro, "Shear strength and stiffness of expansive soil and rubber (ESR) mixtures in undrained axisymmetric compression," Geo-Frontiers Congress, Reston, VA, USA (2011).

[5] P. Anbazhagan, M. Mamatha, P. Soumyashree, N. Sushyam, T. P. Bharatha, and R. W. Vivekan, "Laboratory characterization of tyre crumbs soil mixture for developing low cost damping materials," IJEE, 4(6), 63-66(2011).

[6] M. Ehsani, N. Shariatmadaria, and S. M. Mirhosseini, "Experimental study on behavior of soil-waste tire mixtures," Scientia Iranica. Transaction A, Civil Eng., 24(1), 65-71(2017).

[7] C. Lee, Q. H. Truong, and J. S. Lee, "Cementation and bond degradation of rubber-sand mixtures,” Can. Geotech. J., 47(7), 763-774 (2010).

[8] S. M. Tafreshi, G. T. Mehrjardi, and A. R. Dawson, "Buried pipes in rubber-soil backfilled trenches under cyclic loading," J. Geotech. Geoenviron., 138(11), 1346-1356 (2012).

[9] M. Saberian, M. Mehrinejad Khotbehsara, S. Jahandari, R. Vali, and J. Li, "Experimental and phenomenological study of the effects of adding shredded tire chips on geotechnical properties of peat," Int. J. Geotech. Eng., 12(4), 347-356 (2018).

[10] A. Anastasiadis, K. Senetakis, K. Pitilakis, C. Gargala, and I. Karakasi, “Dynamic behavior of sand/rubber mixtures. Part I: Effect of rubber content and duration of confinement on smallstrain shear modulus and damping ratio," Journal of ASTM International, 9(2), 1-19 (2012b).

[11] T. B. Edil, and P. J. Bosscher, "Engineering properties of tire chips and soil mixtures," Geotech. Test J., 17(4), 453-464 (1994).

[12] G. J. Foose, C. H. Benson, and P. J. Bosscher, "Sand reinforced with shredded waste tires," Journal of Geotechnical Engineering, 122(9), 760-767 (1996).

[13] G. V. Rao, and R. K. Dutta, "Compressibility and strength behaviour of sand-tyre chip mixtures," Geotech. Geol. Eng., 24(3), 711-724(2006).

[14] S. Kawata, M. Hyodo, P. Orense, S. Yamada, and H. Hazarika, "Undrained and drained shear behavior of sand and tire chips composite material," Proceedings of the international workshop on scrap tire derived geomaterials-opportunities and challenges, Yokosuka, Japan (2007).

[15] M. Neaz Sheikh, M. S. Mashiri, J. S. Vinod, and H. H. Tsang, "Shear and compressibility behavior of sand-tire crumb mixtures,” J. Mater. Civil Eng., 25(10), 1366-1374 (2012).

[16] S. Youwai, and D. T. Bergado, "Strength and deformation characteristics of shredded rubber tire sand mixtures," Can. Geotech. J, 40(2), 254-264 (2003). 
[17] H. Cetin, M. Fener, and O. Gunaydin, "Geotechnical properties of tire-cohesive clayey soil mixtures as a fill material," Eng. Geol., 88(1-2), 110-120 (2006).

[18] S. Akbulut, S. Arasan, and E. Kalkan, "Modification of clayey soils using scrap tire rubber and synthetic fibers," Appl. Clay Sci., 38(1-2), 23-32 (2007).

[19] P. Gotteland, S. Lambert, and L. Balachowski, "Strength characteristics of tyre chips-sand mixtures," Studia geotechnica et mechanica, 27(1-2), 55-66 (2005).

[20] A. H. Al-Rkaby, and Z. M. Alafandi, "Size Effect on the Unconfined Compressive Strength and Modulus of Elasticity of Limestone Rock," Electronic Journal of Geotechnical Engineering, 20(12), 1393-1401(2015).

[21] A. H. Al-Rkaby, A. Chegenizadeh, and H. R. Nikraz, "Cyclic behavior of reinforced sand under principal stress rotation," Journal of Rock Mechanics and Geotechnical Engineering, 9(4), 585-598(2017).

[22] A. H. Al-Rkaby, A. Chegenizadeh, and H. R. Nikraz, "Anisotropic strength of large scale geogrid-reinforced sand: experimental study," Soils Found., 57(4), 557-574 (2017). 